\title{
CarryIT: Design and Implementation of an Effective Parcel Carrying System
}

\author{
Khandaker Mohammad Mohi Uddin ${ }^{\text {a*, }}$ Md Razwanul Ghania ${ }^{a}$ Kazi Hozayfa Ahsan ${ }^{\mathrm{a}}$, Rafid Mostafiz ${ }^{\mathrm{a}}$, \\ and Samrat Kumar Dey ${ }^{\text {a }}$ \\ ${ }^{a}$ Dhaka International University, Dhaka, Bangladesh \\ Email address: jilanicsejnu@gmail.com
}

Received: 19 February 2021; Accepted: 20 March 2021; Published: 08 June 2021

\begin{abstract}
A plethora of courier services are available in Bangladesh which are more expensive, less effective and takes ages to deliver the product. Besides, in the ongoing COVID-19 pandemic situation, it's onerous to move from one place to another, and if a person wants to send a product, he/she needs to go to the courier office. Moreover, many people need to move from their house for attending office, meetings, and traveling from one district to another district for special purposes. In this paperwork, a system is introduced to reduce the cost and time to send a product from one place to another place. Basically, an application is developed to meet the people who want to send a product and another one who want to carry the product. For carrying the product one can easily earn money. After scrutinizing the cost of courier services in Bangladesh, an algorithm is introduced to calculate the carrying cost of the product and an algorithm is also developed for product security.
\end{abstract}

Index Terms: Courier services, Travelling, Parcel, Delivery, Security.

\section{Introduction}

Every second, a number of parcels are sent from one place to another place all over the world. People use courier service to save their traveling time and cost. Day-by-day courier services have become more popular all over the world. Locally or worldwide, there are numerous courier services available. Before the innovation of vehicles, people use runners to send their parcels from place to place. The runner was a person who carries parcels of the sender but it takes a long time to send a parcel. Now in the $21^{\text {st }}$ century, a lot of courier service companies are introduced to carry parcels of the senders. These companies provide services in a country or all over the world. Bangladesh is a fast-growing economic country in the world. There are more than 100 courier companies that are providing service to transmit parcels from one place to another place and few companies are introduced to carry parcels to or from abroad.

Courier service is an outsourcing medium company whose responsibility is to transport goods of a customer from one geolocation to another [1]. Basically the goods are related to the delivery of packages, documents, parcels and letters [2]. Nowadays, Courier service companies also transport daily necessary products. The demand for courier service is increasing day-by-day and people randomly use courier service than before. Besides, in the COVID-19 pandemic, it is very risky to go outside, for which, people are going to use courier service to send their parcels. It takes time to send a parcel and sometimes the courier service company does not provide any reliable security.

People who do not have their own transportation (vehicles) for traveling from one place to another, face difficulties to send their parcels [3]. This problem will be acute when an individual initiates to execute the operation of delivering parcels and products. So, door-to-door consignment service can be an invaluable help for the individual [4]. To get rid of these problems an application is introduced where people don't need to go outside from their house to send a product, they just have to log-in to this application and find a person who will go to their destination where they want to send the product. This application suggests the sender finds the nearest user who will go to the same destination and then the user who will go the destination can carry the product at a minimal cost. An algorithm is introduced after analyzing the different courier service companies in Bangladesh to calculate the carrying cost of the product. For providing security, an algorithm is also developed.

Every day people are moving from one place to another for doing their job, enjoying the vacation, visiting their relative or friends and so on. So, while they are traveling from one place to another place if they carry a product to the same destination where they go, it would be very helpful for them to help others and also earn some money. In a rural area of Bangladesh, where there is no courier service company, it is difficult to send a parcel from one place to place. So, using this application sender can easily send their parcel to the destination without any fare. Besides the person who carries the parcel can earn money while visiting one area to another area. On the other hand, in a city where there are a 
plethora of people moving from one place to another, they can easily earn money by carrying the parcel with them to their destination.

For background study, the working procedure, terms and conditions, and courier service rate of a few courier service companies are analyzed. Sundarban courier, Pathao courier, eCurier, Janani courier are the top courier service companies in Bangladesh. These companies charge 60-100 taka to deliver the parcel inside the Dhaka city within 1 or 2 days. However, these companies take 100-250 taka to deliver the parcel outside the Dhaka city within 2-7 days. After analyzing the rules of these currier service companies, an algorithm is developed for the security of this application and also developed an algorithm to calculate the optimal cost for carrying a product. The distance of different districts of Bangladesh is observed to develop an algorithm to calculate the carrying cost [5].

There are many ride-sharing companies like Pathao, Uber, Shohoz, Obhai, and Obhon that are popular in Bangladesh [6]. In addition, there are many food delivery companies that are also popular in Bangladesh like Foodpanda, HungryNaki, Pathao Food, Shohoz Food, and KhaasFood [7]. While designing and developing this application, the working procedure of these ride-sharing and food delivery applications are also monitored.

Lin et. al. analyzed the business services, operations and environment of e-commerce where courier services are not adequate to deliver the products [8]. For Express and Parcel (CEP) services Niels et. al. [9] designed and implemented an urban logistics system in Munich, Germany to deliver the product door-to-door using cargo bikes and eBike. Apart from this, their developed system also finds the optimal route to deliver the product and ensure on-time delivery.

Huang et. al. [10] proposed a parcel delivery system which is formed by a public train and an unmanned aerial vehicle (UAV). In their system, a UAV is basically used to deliver the parcels, and to minimize the delivery time they developed a suboptimal algorithm. They have found that their system can cover a large area than only the UAV delivery scheme and more cost-effective than the Truck only scheme or Truck plus UAV scheme.

The indispensable contributions of this work are given as follows:

- Develop an application to match people who want to send their parcels and the people who willing to help them while traveling and earn money.

- $\quad$ Provide security while carrying a parcel.

- Reduce time and money to send a parcel.

- Develop an algorithm to calculate an optimal parcel carrying cost.

\section{Methodology}

To implement this proposed system, a PHP framework laravel and a feature of JavaScript (JS) called Ajax to retrieve data from the database are used to develop this proposed system. Here the MySQL database server is used. Bootstrap is used while developing this application so that users can use it by means of their mobile phone. The main features of this application are:

\section{A. User registration through SMS verification \\ B. Create post \\ C. Create request \\ D. Assign carrier \& receive courier}

A Data-flow Diagram (DFD) is used to graphically represent the flow of data in a system. The data flow diagram of this project describes the processes that are involved in a system to transfer data from the input to the file storage and retrieve it from the database to show it in the user interface.

\subsection{User registration through SMS verification}

A user registration process is a very important part of any application. From this process, we can get all the necessary information about a user. After completing the registration process by providing valid information, a user can $\log$ in to the system. In order to be logged in, a user has to fill up all the required field in the registration form. After completing the registration, a user has to verify his identity through SMS verification. All the registration information is stored in the user database. Then again providing the Email and password in the login field, the user can log in to the system "Fig. 1" shows the steps of the registration process through SMS verification.

\subsection{Post Creation}

In order to create a carrier post, a user has to click on the create post option. Then he/she has to provide the necessary information like title and date, from-address and to-address, and also the travel details information in the box. After providing all this information a user can create a carrier post. All this information is stored in the carrier post database. The user can also view all his carrier post from "my post" option. A user who travels from one place to another can create a carrier post. 


\subsection{Request post}

If carrier post does not exist for a particular location a user can also create a request post. In order to create a request post, user has to click on create request option then user has to choose the date duration frame and then the source to the destination location. Again all this information is stored in the request post database. This post can be viewed from my request option. A user can also create a request post to carry his/her parcel within a given time period.

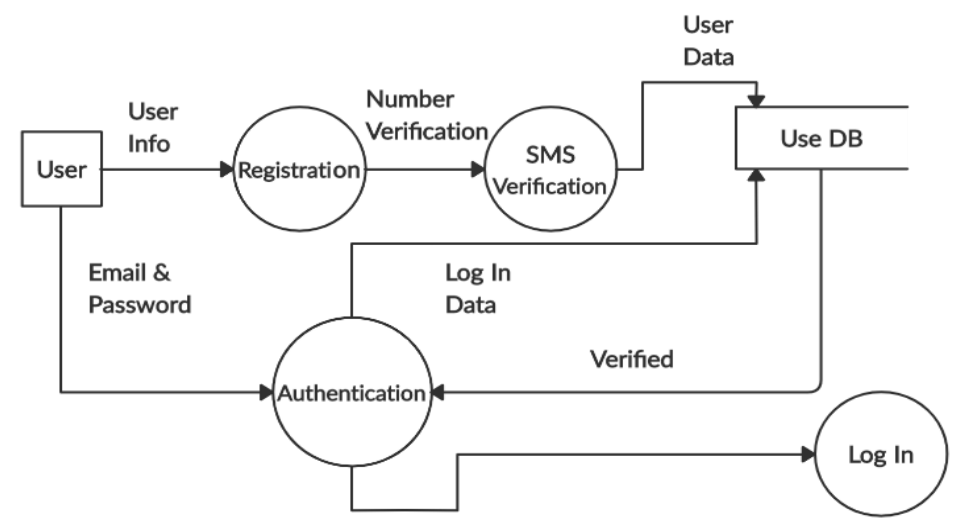

Fig. 1. Data flow diagram for user registration.

\subsection{Assign carrier \& receive courier}

Assign and deliver option is the most crucial part of this system. If a user wants to send a parcel from source to a destination location, he/she has to look at the career post option first. If any available carrier post matches his/her source with the destination location, the sender user can assign his parcel to the carrier. In order to assign a parcel to a carrier user, the sender user has to provide the necessary information like the total weight of the parcel, information of the parcel receiver and the image of the parcel. All this information is stored in 'carries' database. Then it comes to the carrier user, who has the choice to accept the carry request assigned by the sender user. Then after the carrier user accepts the carry request, the sender user can handover the product to the carrier user who then carries the parcel from source to destination and gives it to the predefined receiver. At last, after the receiver receives the parcel, user has to provide a passphrase in the passphrase box which is in the receive option on this website to ensure that the parcel arrived properly. He/she can also provide ratings to the carrier.

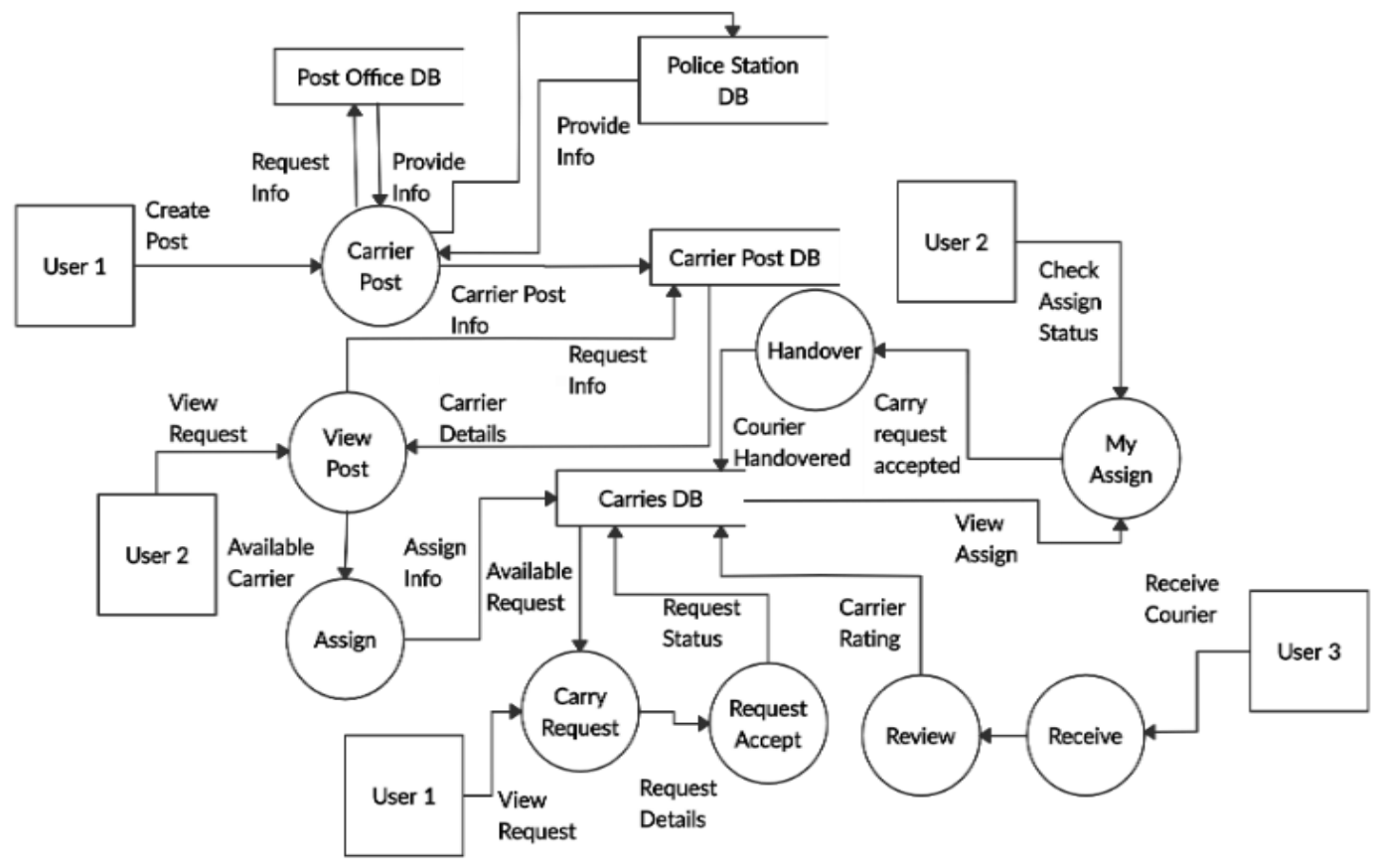

Fig. 2. Data flow diagram for assign and receive the parcel 
Sender can assign a carrier to carry his parcel with the receiver's mobile number. Then if the carrier accepts sender request, the sender can handover the product. After that, when the receiver receives the product, he/she has to enter the passphrase to confirm that parcel successfully transferred from sender to receiver. "Fig. 2" shows the procedure of assign and receive the parcel. Only registered users can use this proposed application. In this application, user information is stored in a MySQL database and authorizations are done after accessing the database. After receiving a successful product delivery the each and every detail are kept in the database.

\section{System Architecture of the Work}

The Major features of this proposed system are given as follows:

1. Firstly, one person can easily find someone who wants to travel the same destination address of that person. If the person finds no one to travel to the destination place he/she can make a post for carrying his/her product.

2. Secondly, the carrier can earn money by parceling the products.

3. An algorithm is developed to calculate the optimal charge to carry the parcel.

Basically, this system is helpful to match the people who wants to send their parcel and who wants to carry it, provided they have the same destination. The person who carries the parcel can be benefited by earning money.

This system allows to carry a maximum of $5 \mathrm{KG}$ of any product and according to the distance, the cost will be different. Let, Product weight is denoted by " $\mathrm{w}$ ", distance is denoted by " $\mathrm{m}$ " and Carrying Cost is denoted by "CC". When distance is less than $100 \mathrm{~km}$ using equation-1 Carrying Cost can be calculated.

When the distance is between $100 \mathrm{~km}$ to 250 then equation- 2 is used to calculate the carrying cost. Here, $0.07 \mathrm{used}$ as a constant value. For the distance between $251 \mathrm{~km}$ to 400 , a 0.045 constant value is used which is given in equation-3 and a 0.032 constant value is used to calculate the carrying cost when the distance is between $401 \mathrm{~km}$ to $650 \mathrm{~km}$ which is given in equation-4. The working procedure of a carrier is illustrated in "Fig. 3". Algorithm 1 shows the cost calculation for the carrier to carry a product.

$$
\begin{gathered}
C C=30+m * w * 0.1 \\
C C=40+m * w * 0.07 \\
C C=60+m * w * 0.045 \\
C C=65+m * w * 0.032
\end{gathered}
$$

\section{Algorithm 1: Calculating cost according to product weight and destination distance}

Input: Product Weight (w) in KG, Destination Distance (m) in KM

Output: Carrying Cost (CC)

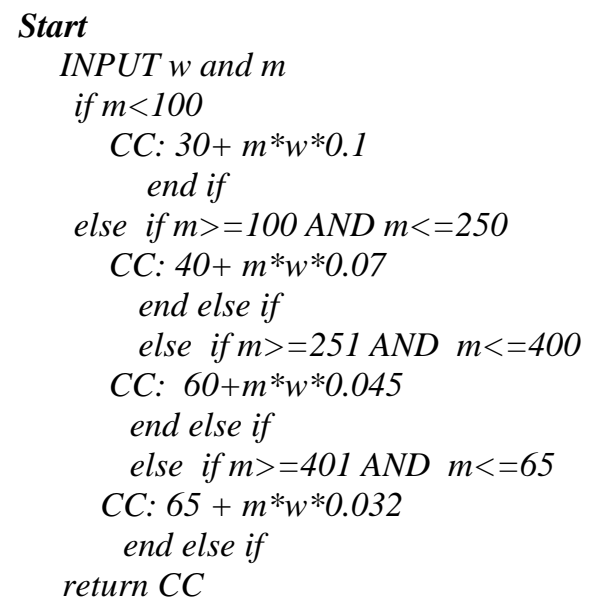

\section{End}




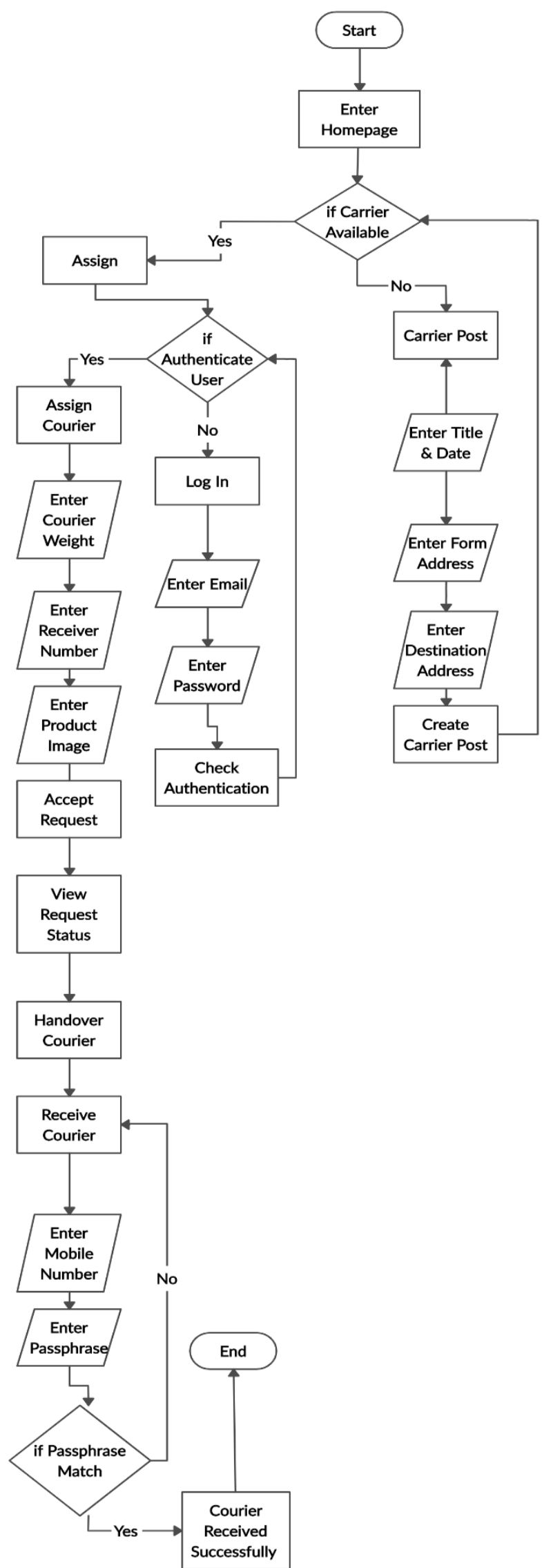

Fig. 3. Working Procedure of a Carrier 


\section{Working Procedure of the Proposed System}

Let us assume person $\mathrm{X}$ is about to travel from place A to place $\mathrm{B}$. He is thinking that he might be able to carry some product along with him. Then person X will come to this interface and sign up/Login there as shown in "Fig. 4".
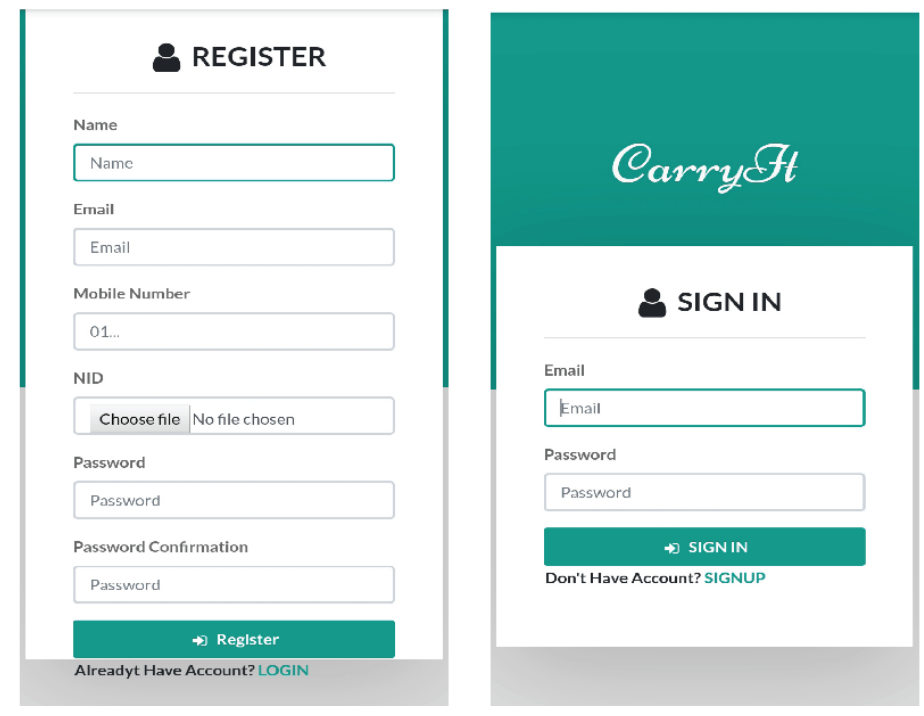

Fig. 4. User interface of the system

Then he/she will create a post describing his/her starting place to ending place followed by a brief information about the product type he/she wants to carry with as shown in "Fig. 5".
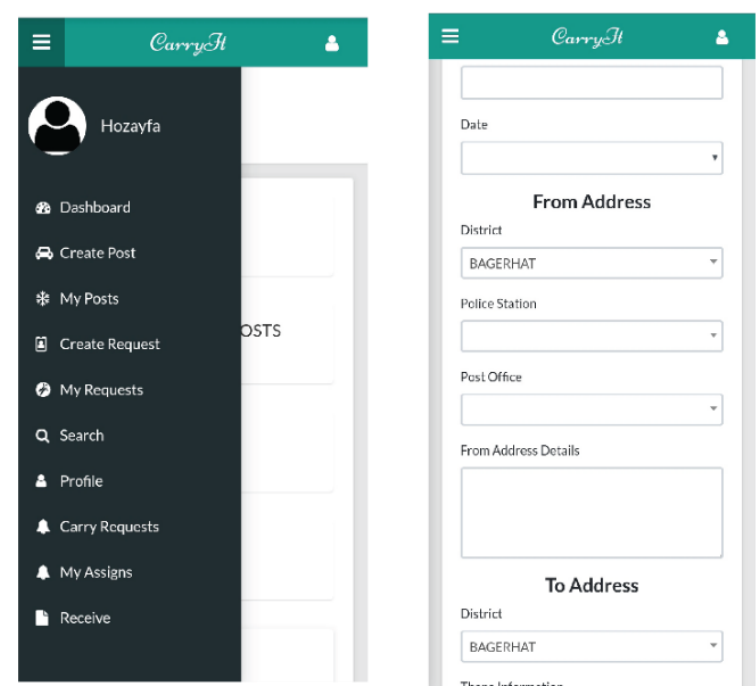

Fig. 5. User interface to create a post to carry a product

Once a post is created it will be shown on the home interface. As shown in "Fig. 6". Then person Y wants to send a parcel from place A to place B. He/she at first comes to this interface, searches for his/her necessary posts. If he/she finds a match then he/she requests person $\mathrm{X}$ to carry his/her product along with him during travel. 


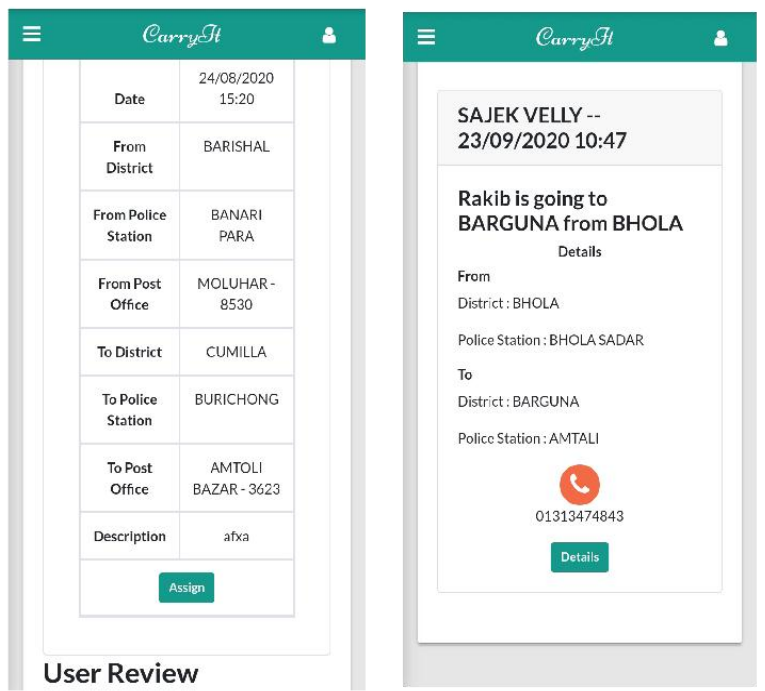

Fig. 6. Post created by a carrier

Person X gets SMS on his mobile phone saying a request has been created against his post. If he finds it suitable, he accepts. Another SMS is sent to Person Y notifying that his request has been accepted. Then person Y hands over his parcel to person X. During the request process person Y needs to mention the receiver's name and mobile number. When the parcel is handed over the receiver will be notified of a passphrase via SMS. During the receiving process, the receiver is asked to provide the passphrase sent to his mobile phone followed by his mobile number. If the above information is correct then the parcel is registered as received. Person $\mathrm{Y}$ is being asked to provide a user review for person $\mathrm{X}$ for his service which is given in "Fig. 7".

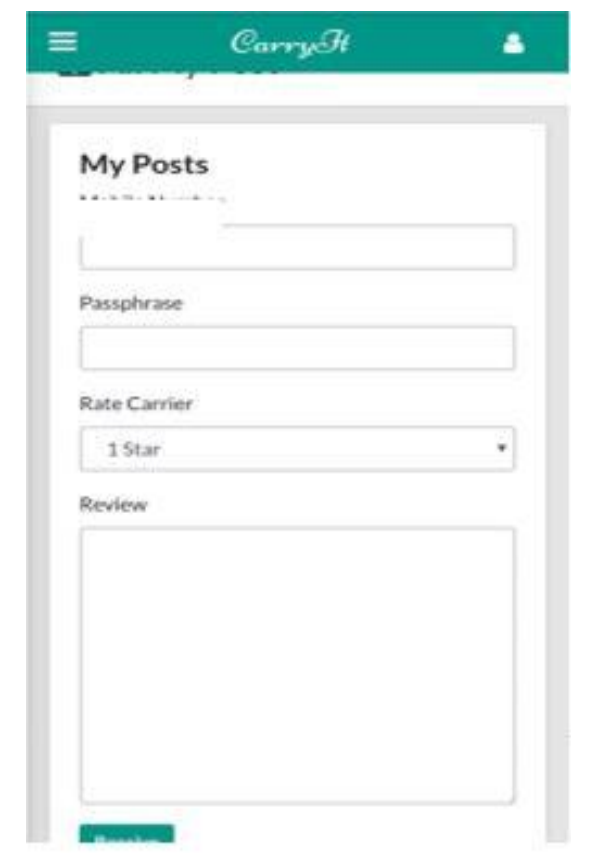

Fig. 7 Passphrase and rating interface for the receiver

\section{Experimental Result}

This application has been tested with the 10 project members and their mates who have the experience of using interactive smart devices. We have done 50 complete tests where one gives the parcel request and someone else can respond to this request, and one can provide traveling information by which the sender can find this person. The outcomes of these tests are: 
1. Initially, 10 individuals registered in this system where one person got mobile verification message 5 minutes later due to his poor mobile network. Otherwise, each time registrations were done smoothly with mobile verification. The times to get a verification message are shown in Table 1. First, sixth and seventh participants got verification messages in 2 seconds however ninth participant got the verification message after 5 minutes.

2. Requesting for a carrier or responding as a carrier worked successfully.

3. Each time, for providing security, passphrases are generated perfectly. Table 2. shows the average passphrases generating time of 50 testes. For doing 31-35 number testes average passphrases generating time is 1.75 seconds and 2 seconds is for 26-30 number of testes. It is observed that for doing 6-10 tests it took an average of 5 seconds.

4. Rating system also worked utterly well and added to the user profile.

5. Delivery costs are generated according to the proposed algorithm without any transgression.

Table 1. Time to get verification message of 10 individuals.

\begin{tabular}{|c|c|}
\hline Participants & Time to get verification message (seconds) \\
\hline PN-01 & 2 \\
\hline PN-02 & 6 \\
\hline PN-03 & 3 \\
\hline PN-04 & 3 \\
\hline PN-05 & 4 \\
\hline PN-05 & 12 \\
\hline PN-06 & 2 \\
\hline PN-07 & 2 \\
\hline PN-09 & 300 \\
\hline PN-10 & 7 \\
\hline
\end{tabular}

Table 2. Average passphrases generating time of 50 testes.

\begin{tabular}{|c|c|}
\hline Number of testes & Average passphrases generating time (seconds) \\
\hline $1-5$ & 3.5 \\
\hline $6-10$ & 5 \\
\hline $11-15$ & 3 \\
\hline $16-20$ & 2.5 \\
\hline $21-25$ & 4.75 \\
\hline $26-30$ & 2 \\
\hline $31-35$ & 1.75 \\
\hline $36-40$ & 5 \\
\hline $41-45$ & 3.75 \\
\hline $46-50$ & 2.5 \\
\hline
\end{tabular}

Sundarbon Courier Service, Delivery Tiger, Pathao, REDEX delivery, and eCourier are the popular courier service companies in Bangladesh. To deliver the courier inside Dhaka city they take 24 hours and outside of Dhaka city they try to deliver the courier within 3-4 days [11]. Table .3 shows the delivery time of different courier companies in Bangladesh. For delivering a courier inside the Dhaka city, proposed CarryIT takes few hours and for the outside of the Dhaka city, it takes a maximum of 10-12 hours. Based on the above discussion it is concluded that our proposed CarryIT provides quick delivery than other existing courier service companies. 
Table 3. Comparison of the delivery time of different Courier Service companies in Bangladesh.

\begin{tabular}{|c|c|c|}
\hline Courier company & Delivery time Inside Dhaka & Delivery time Outside Dhaka \\
\hline Sundarbon Courier Service & 24 hours & Within 3 working days \\
\hline Delivery Tiger & 24 hours & Within 4 working days \\
\hline Pathao & 24 hours & Up to 3 working days \\
\hline REDEX delivery & 24 hours & Within 3 working days \\
\hline eCourier & 24 hours & Within 3 working days \\
\hline Our Proposed method (CarryIT ) & Within few hours & Maximum 10-12 hours \\
\hline
\end{tabular}

Though Sundarbon Courier Service and Delivery Tiger have branches in 64 districts in Bangladesh, the rest of the courier service companies provide their service in only 40-55 districts. Using CarryIT, it can be possible to send a parcel or courier from one district to another one where there are no courier services companies. The services covering by the courier service companies in Bangladesh are shown in Table 4.

Table 4. Covering area of different courier service companies in Bangladesh.

\begin{tabular}{|c|c|}
\hline Courier company & Covering area \\
\hline Sundarbon Courier Service & 64 districts with more than 650 braches \\
\hline Delivery Tiger & 64 districts and more than 490 sub-districts \\
\hline Pathao & 50 districts \\
\hline REDEX delivery & 50 districts \\
\hline eCourier & All districts and sub-districts \\
\hline Our Proposed method (CarryIT ) & 50 \\
\hline
\end{tabular}

\section{Conclusion}

In the era of rapid technology advancement of courier services, applications are widely used. This developed application has become important for the people who frequently want their items to be delivered and also who are conducting online businesses. Besides this application helps those people who frequently travel from one place to another place to earn money by carrying the product of the sender. The developed algorithm provides security and calculates the optimal cost for the sender. It also helps to find the nearest person who wants to travel to the same destination where the user wants to send his/her product. The user rating system also helps to find out a reliable user. For future enhancement, a real-time tracking system will be included that will help the sender to track the person who carries his/her parcel.

\section{References}

[1] M.N. Agu, C.I. Nwoye and B.O. Ogbuokiri. "Enhancing Courier Service with the Devel-opment of an Interactive Mobile App in Android Platform', IOSR J. Mobile Comput.Appl, (IOSR-JMCA). e-ISSN, pp.2394-0050, May - Jun 2015.

[2] Izzah, Nurul, D. Rifai, and L. Yao. "Relationship-courier partner logistics and e-commerce enterprises in malaysia: A review." Indian Journal of Science and Technology 9, no. 9, Mar 2016.

[3] "United Nations, Department of Economic and Social Affairs, Population, Division" Accessed: Jun. 20, 2020. [Online]. Available: http://www.un.org/en/development/desa/publications/world-populationprospects-2015-revision.html

[4] E.B. Prince and K.A. Bakon. "A Study on The Need to Implement a Courier Service Appli-cation on Android Smartphones" International Journal of Information System and Engineer-ing, vol4, no.2, Nov 2016.

[5] "Bangladesh Districts Information," Accessed on: May. 10, 2020. [Online]. Available: https://www.citypopulation.de/Bangladesh-Mun.html

[6] "Popular Online Food Home Delivery Services In Bangladesh," Accessed on: Jun. 24, 2020. [Online]. Available: https://deshiz.com/online-food-delivery-bangladesh/ 
[7] "Popular Online Ride Sharing Services In Bangladesh," Accessed on: Jun. 25, 2020. [Online]. Available: https://insiderbd.com/en/top-five-ride-sharing-app-in-bangladesh/

[8] C. Lin, K. L. Choy, G. T. Ho, and H. Y. Lam.” A decision support system for optimizing dynamic courier routing operations.” Expert Systems with Applications, vol 41, no.15, pp 6917-6933, Nov 2014.

[9] T. Niels, M.T.Hof, and K. Bogenberger, "Design and Operation of an Urban Electric Courier Cargo Bike System, "2018 $21 \mathrm{st}$ International Conference on Intelligent Transportation Systems (ITSC), Maui, Hawaii, USA, November 4-7, 2018.

[10] H. Huang, A. V. Savkin and C. Huang, "Optimal Control of a Hybrid UAV/Train Parcel Delivery System," 2019 Chinese Control Conference (CCC), Guangzhou, China, 2019, pp. 6606-6609, 2019.

[11] "Best Online Courier and Delivery Services In Bangladesh," Accessed on: Jan. 25, 2021. [Online]. Available: https://deshiz.com/online-courier-delivery-services-bangladesh/

\section{Authors' Profiles}
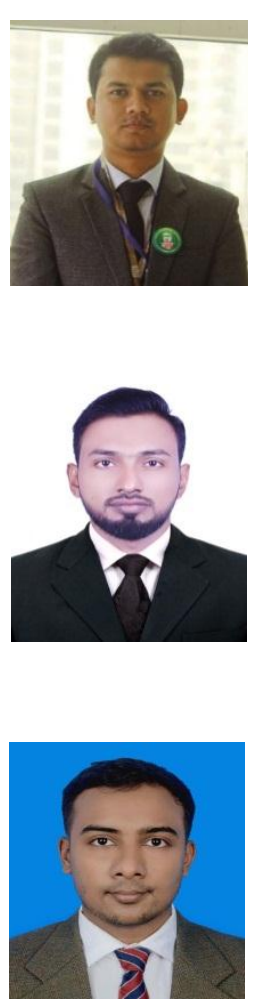

Md Razwanul Ghani was born in 1993 in Rajshahi, Bangladesh. He has completed his B.Sc degree in Computer Science and Engineering from Dhaka International University in 2020 and continuing M.Sc. in CSE in the same university. He has experience of working as a software engineer for two years.

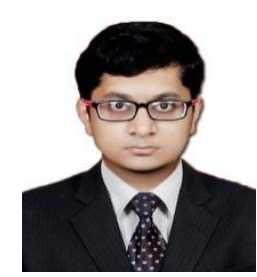

Rafid Mostafiz is working as an Assistant Professor at Dhaka International University in the Computer Science and Engineering department. He has completed his Master's (MSc.) and Bachelor's (BSc.) Degree in Computer Science and Engineering from Mawlana Bhashani Science and Technology University, Bangladesh. Rafid does research in Computer Vision and Image Processing, Medical Imaging, Deep Learning, Artificial Neural networks, Software Defined Networking and Algorithms.

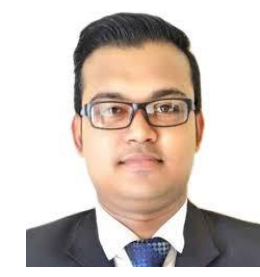

Samrat Kumar Dey is an Assistant Professor in the Department of Computer Science and Engineering at Dhaka International University. He has completed his Bachelors and Masters in Computer Science and Engineering (CSE) from Patuakhali Science and Technology University (PSTU) and Military Institute of Science and Technology (MIST) respectively. His research interest mainly focuses on Data Science, Visual Data Analytics, Human-Computer Interaction (HCI), Usability and UX analysis, Machine Learning/Deep Learning and Network Security. 
How to cite this paper: Khandaker Mohammad Mohi Uddin, Md Razwanul Ghani, Kazi Hozayfa Ahsan, Rafid Mostafiz, Samrat Kumar Dey, " CarryIT: Design and Implementation of an Effective Parcel Carrying System", International Journal of Education and Management Engineering (IJEME), Vol.11, No.3, pp. 20-30, 2021. DOI: 10.5815/ijeme.2021.03.03 